\title{
EL SENTIDO DEL VALOR O EL VALOR EN CUESTIÓN
}

\section{Álvaro Carrión*}

La reflexión sobre el problema del valor y lo relativo a lo que le caracteriza y le otorga un determinado estatuto, pone en evidencia la complejidad de tal temática, si lo ubicamos en un orden que haga énfasis en la riqueza de sus determinaciones. Por otra parte, la idea de valor no se restringe al campo axiológico, sino a ámbitos tan diversos como el de la economía, la estética y la lógica. Los tres últimos campos no son los que van a ser considerados en este artículo y remiten a disciplinas en las que no buscamos indagar ya que la investigación que nos proponemos se circunscribe al orden del actuar y al

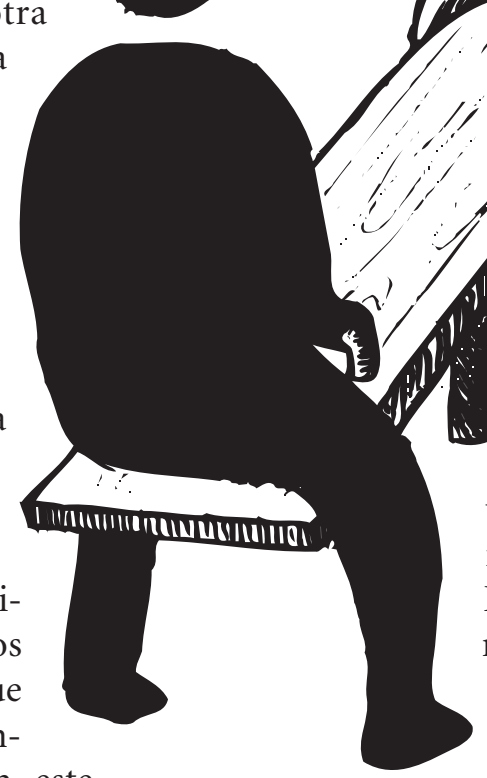

estructuración psíquica y que pertenecen a un ámbito tan prolífico en cuestiones relativas a la producción subjetiva e inter-subjetiva como el Psicoanálisis, en una dirección que

* Psicoanalista. Pontificia Universidad Católica del Ecuador (PUCE). 
busca situar a un sujeto desde el estudio del entramado metapsicológico, que conlleva una explicación teórica de la urdimbre de nexos psíquicos que dan cuenta de la construcción subjetiva de un sujeto social y de las pautas que le constriñen y le son inherentes como elementos constitutivos de su mismidad.

\section{Aportes de la Filosofía: deber, ley, libertad y valor}

El problema del valor o de los valores, que se desarrollará en las formulaciones siguientes, parte de un acercamiento desde posiciones filosóficas que indagan en el campo de la Ética, en una vertiente de reflexión que puede ser cuestionada, negada, $\mathrm{o}$ revisada, pero de la que no se puede prescindir. Esta es la propuesta relativa a la Filosofía Crítica que apunta al tema de las costumbres y a una Filosofía Práctica, para, siguiendo los hilos de su propuesta, en especial relativos a ciertos problemas que aparecen en algunas de las reflexiones éticas posteriores a las de Kant, señalar, finalmente, a los valores como centro de sus programas éticos. Este acercamiento a la cuestión, sumado al ensayo sobre lo psíquico y los valores, sostienen una tesis que señala al tema de los valores en términos de una educación en valores, como una equívoca postura para reproducir propuestas ideológicas que no responden a la densidad de los desarrollos éticos ni a las consecuencias derivadas en su reflexión, sino más bien a una respuesta frente a los cambios históricos que aparecen en una sociedad en crecimiento que adquiere una complejidad mayor en la contemporaneidad.

El campo de los valores y la reflexión sobre los mismos, como toda elaboración que se remite a un orden discursivo de abstracción, está sembrado de problemas que hacen a la forma o al principio, a partir del cual se parte para la formulación y dilucidación de las construcciones a las que se llega en una determinada forma expositiva. En este sentido, no podemos, al hablar de valores, referirnos a una consideración única, a la que todos nos remitamos como un campo unificado y transparente de argumentos. Peor todavía a un asunto, que por el uso frecuente del término valor o valores, sea parte del sentido común, de $l o o b v i o^{1}$, o de un

1 En el uso que hace R. D. Laing del mismo, en tanto justificación de acontecimientos, hechos y circunstancias, a partir de las cuales se generan guerras, crímenes, etc. 
orden como el de la opinión, sustentado, en este sentido, en una idea poco clara y distinta como ideología de lo que debe ser, según el dictado de una óptica individual o de una colectividad en determinados momentos históricos, desde una mirada de clase social o relativa a determinadas coyunturas. El sentido deíctico que adquiere el no al que nos referimos, busca delimitar dos espacios que cuentan de forma significativa en los abordajes a la órbita de los valores: por un lado, las concepciones de los mismos y, por otro, el discurso de la doxa, de lo ya sabido en la inmediatez, de lo intuitivo y poco fundamentado. Ubicar tanto un espacio como el otro, nos permite reflexionar sobre la ubicuidad que adquiere la temática en momentos de cambio y el imperativo de un pensamiento que permita esclarecer el ¿por qué pensamos de una forma determinada sobre un objeto (valor) y proponemos, normativamente, hacer, desde una idea regulativa? Conocimiento y acción, acorde a él, que esperamos, no responda a una ética intelectualista del fundamento del actuar. Cuestión que nos previene con respecto a las éticas de los bienes y los fines, que a partir de la filosofía crítica kantiana quedan objetadas desde un discurso riguroso, pero, y, a su vez, polémico por su extremo formalismo. Figura, la de las éticas de los bienes y los fines, que pone en consideración el tema del relativismo y el fundamento empírico del actuar moral y que evaden la fundamental diferenciación entre ética y moral, tan cara a la filosofía kantiana. Temáticas que requieren ser desarrolladas para poder considerar de forma compleja las implicancias de lo que, posteriormente, podemos llamar axiología, sin pasar a una revisión más exhaustiva de lo que implica la opinión o doxa, ya que con lo ya dicho la hemos caracterizado de manera suficiente.

Si partimos de la crítica realizada por Kant a las concepciones tradicionales sobre el bien, que tienen, en su gran mayoría, un fundamento racional, encontramos una diferencia substancial relativa al concepto de razón. Las concepciones tradicionales se fundan en una noción de razón que distante a la voluntad dicta sus leyes de forma heterónoma. Al estar alejada la voluntad de la razón y al ser esta última la que sabe previamente qué es el bien y qué es el mal, el sujeto conoce cuál debe ser el actuar moral. En las éticas tradicionales la motivación de la acción moral depende de un código o decálogo impuesto por una voluntad 
ajena al individuo (razón divina), a diferencia de aquella otra en la que se piensa a la razón como suprema directora de lo que la voluntad debe o no hacer (ética de la perfección). En Kant la razón es práctica, en la medida que al darse a sí misma (voluntad) la ley, necesita de la razón para actuar de acuerdo a ella, ya que sólo la razón puede representarse la ley, a la vez, que sólo ella puede derivar las acciones de las leyes, por lo que y de esta forma, la voluntad es razón práctica. En esta perspectiva podemos ver, de manera implícita, como el concepto de autonomía cobra vigencia, como noción propiamente moderna, modernidad que se reafirma en el pensador que inaugura la filosofía crítica. Autonomía, decíamos, que como voluntad se da a sí misma la ley, como principio objetivo que se constituye en determinación de la voluntad.

Un trabajo que nos orienta de forma especial sobre la ética, dentro de la reflexión que inicia Kant, es el de la Fundamentación de la metafísica de las costumbres, obra en la que el autor busca ir desmenuzando de forma analítica y regresiva lo que la razón común vive como un comportamiento moral, a la vez que fija los límites que esa moral vulgar tiene, a través de conceptos (deber, respeto, máxima, ley, moral, autonomía, libertad) para, de esta forma, llegar progresivamente a una síntesis. El método que guía a Kant, el método trascendental, le permite no situarse desde la óptica del objeto fenoménico de la moralidad, sino de la forma de conocer al objeto que la voluntadrazón se da a sí misma. En este sentido, el orientarnos en materia moral es para el pensador alemán el poder discriminar entre el bien y el mal, hecho que se plasma a través de la legislación que se da a sí mismo el sujeto moral, reflejada en su propio actuar y que hace de su máxima, que en un inicio tiene un carácter subjetivo, ley universal con carácter objetivo y necesario. Este último tema planteado de la forma por la que hemos optado requiere de mayor desarrollo.

En la obra mencionada de Kant, la que se escribe con el objeto de explicar y clarificar los principios de la moralidad, se desarrolla una argumentación que parte de un camino que le lleva de la buena voluntad a la formulación del imperativo categórico. Este último surge de la voluntad del sujeto para tomar distancia de lo sensible (libertad negativa), de la que se evidencia su condición de sujeto sometido, parcialmente, a sus apetitos, a sus inclinaciones, a su sensibili- 
dad, y el actuar con apego a la razón. El individuo es para Kant un ser finito, que puede actuar no sólo por lo que le dicta su razón, sino por su naturaleza sensible, es así que el actuar fundado en la razón se torna una constricción para la sensibilidad, un imperativo y un deber, en función de la ley. La ley se le impone a la razón como un hecho, de allí su calidad de imperativo. El imperativo es, en la razón humana, categórico, por la doble condición del sujeto, en su humanidad racional y sensible, para situar su temple racional. El filósofo alemán señala que si los principios prácticos en los que se funda el actuar moral están determinados por un objeto de la facultad de desear, son principios empíricos siempre los que legislan a una voluntad regida de forma contingente y condicionada. El resultado, en ese caso, es que aquellos principios empíricos no pueden constituirse como leyes, carecerían de objetividad quedándose en el mero campo subjetivo.

Por otra parte, la índole racional del imperativo categórico conlleva su forma a priori, asunto que es para la elaboración kantiana de importancia capital, ya que considera que el a priori es compatible con el aspecto sintético. Un juicio sintético a priori en la forma que para Kant tiene, añade un nuevo conocimiento sin la necesidad de la experiencia. Es así que la idea de libertad, que en el mundo inteligible tiene un carácter de posibilidad, como las ideas de la razón que en la razón teórica pueden ser pensadas, pero no conocidas, se conoce en el acto moral, a la vez que y concomitantemente el sujeto moral conoce el absoluto mediante su acción.

Para retomar el asunto del imperativo y las diferentes maneras en las que éste se expresa, nos preguntamos: ¿qué relación teórico-práctica se puede establecer entre las diferentes formulaciones del imperativo categórico? Todas las formulaciones del imperativo categórico son diferentes formas de una misma ley, la que es enunciada desde el modelo de las leyes de la naturaleza, ámbito en el que la ley se cumple de forma inmutable. En el orden moral sería deseable que las máximas elevadas por la persona a ley universal, con el auxilio de la razón, tengan, como en el caso de la naturaleza, un carácter permanente e inalterable.

Las diferentes formulaciones del imperativo categórico, como formas diferentes de expresar la ley, enfatizan diversos aspectos. En la primera formulación: "Obra sólo según una máxima tal que puedas querer al mismo tiempo que se torne ley uni- 
versal", se apunta a que para que se adjetive la máxima, es decir, para que pase de máxima pura a ley, requiere de su universalización, o lo que es lo mismo, que sea válida para todos los seres racionales, incluido el que la formule.

La segunda formulación del imperativo categórico, que es una variante de la anterior: "Obra como si la máxima de tu acción debiera tornarse, por tu voluntad, ley universal de la naturaleza", señala por un lado la autonomía de la voluntad y por otro el carácter de necesariedad que impide que se den excepciones en el cumplimiento de la ley moral.

La tercera formulación: "Obra del modo en que uses la humanidad, tanto en tu persona como en la persona de cualquier otro, siempre como un fin al mismo tiempo y nunca como un medio", estipula que el objeto (materia) de la acción moral debe ser tratado como un fin en sí mismo. Se reconoce así la dignidad del sujeto moral, a la vez que éste adquiere el estatuto de persona.

La cuarta formulación: "La idea de la voluntad de todo ser racional como una voluntad universalmente legisladora", sugiere la idea de la autonomía de la voluntad de todo ser racional para legislar y legislarse universalmente.
Las diferentes formas para expresar el imperativo gravitan en torno de la idea de libertad, en la medida que los conceptos de deber, ley, etc., tienen sentido en función de ésta. El hombre al hacer uso de la libertad en forma negativa, deja de lado las máximas empíricas (sensibilidad, inclinaciones) y opta por las máximas puras. Luego, a través de su universalización, eleva la máxima pura a ley universal, objetiva aquella máxima pura y actúa de acuerdo a ella. En este sentido se habla de un concepto positivo de la libertad como acto creativo, al darse a sí misma (voluntad) su ley, haciendo uso de la autonomía. El sujeto moral es responsable de su acto y en la medida que actúa fundando en la ley su acción le pertenece y puede dar cuenta de ella. En este sentido la acción refleja el nivel de autoconciencia del sujeto moral, a la vez que éste se reconoce en su acto, por lo que la relación entre libertad y responsabilidad se estatuye como necesaria.

La forma en la que desarrolla Kant el problema de la ética, excluye de manera concluyente a los principios materiales por empíricos, como el fundamento del actuar moral, a la vez que los principios inductivos que señalan a la felicidad, el placer, y el bienestar como el supremo bien, y se piensan situados en el origen del 
actuar, son desestimados. Estos aspectos pasan a ser considerados, replanteados y reformulados por un vigoroso pensador como Max Scheler, el mismo que retoma los problemas a los que Kant busca dar respuesta mediante su corpus filosófico, manifestándose interesado seguidor de su doctrina, en cuanto a la posición y crítica de su antecesor a las éticas de los bienes y de los fines, a la vez que se muestra de acuerdo con el planteo apriorístico, pero en la perspectiva de un programa que busca superar el formalismo racionalista de Kant, mediante una ética material de los valores y un apriorismo emotivo. Para Scheler los reproches que se le han hecho al pensador alemán de la filosofía crítica, por filósofos posteriores, no tienen profundidad, además de que no llegan a ser apreciaciones de fondo. Centra su indagación en lo que considera fueron los errores que cometió, el filósofo nacido en Königsberg, en su reflexión: por un lado, el haber confundido lo a priori con lo formal $y$, por otro, equivocar el nexo entre lo a priori y lo racional. Dos asuntos que requieren aclaración: El argumento de Scheler se dirige a establecer que es acertado pensar que los bienes son objetos o cosas valiosas, pero no se puede homologar los bienes a los valores, ya que estos últimos son asimétricos y ocupan una posición diferente e independiente a los objetos empíricos pensados como bienes. Los valores tienen una preeminencia ontológica sobre los objetos que son depositarios del valor. Así, y tomando como ejemplo una analogía, un color es independiente del objeto que lo tenga por cualidad y se hace presente más allá de este o aquel objeto, al igual que una obra musical puede ser considerada bella, sólo y en tanto, la belleza antecede a la obra. Es más, la comparecencia del valor es la que confiere estatuto de bien a un objeto valioso.

La ética Kantiana había formulado y desarrollado la idea que establece que todos los principios materiales son empíricos, a la vez que le es extraña la idea de los valores ya que él parte de que todo principio práctico material o todo objeto de la facultad de desear se constituye en un imperativo hipotético y, por tanto, carente de necesareidad. Mientras Scheler piensa al valor no como fin, sino como objeto material absoluto que no depende de la experiencia y que es producto de una intuición emotiva no racional. Es de esta manera que Scheler esta fundando su postura axiológica en una ética material de los valores $\mathrm{y}$, 
mediante esta propuesta, demuestra que no todas las éticas fundadas en principios materiales son empíricas. La ética scheleriana está fundada en valores universales que tienen carácter a priori $\mathrm{y}$, por tanto, independientes del hecho empírico y de la estimación subjetiva y sin embargo son materiales ${ }^{2}$ a priori.

El problema de los universales es de especial importancia para los dos pensadores alemanes, ya que buscan, en sus formulaciones, establecer un carácter objetivo, absoluto y necesario en la acción ética, alejado de lo relativo y contingente. En ambos podemos vislumbrar, a partir de lo referido, que la idea de necesidad en el plano práctico-moral, es una exigencia de la razón frente a un universal que fundamenta la acción. A la vez que la necesidad revela el enlace a priori entre la razón y el actuar basado en lo que esta dicta a través de la ley. Lo que caracteriza a la necesidad en el plano moral es su independencia de lo empírico y la posibilidad de la voluntad como razón práctica de darse a sí misma la ley.

Los referentes por los que hemos optado señalan algunos de los problemas que se presentan en la elabo- ración de una propuesta fundamentada teóricamente: lo contingente y lo necesario; lo subjetivo y lo objetivo; lo a priori y lo a posteriori; lo empírico-material y lo formal; lo empírico y lo material absoluto; la autonomía y la heteronomía; máximas puras y máximas empíricas; libertad negativa y libertad positiva; etc. Por este camino hemos buscado mostrar algunos de los temas que aparecen ligados a un planteo éticoaxiológico, sin agotar, ni siquiera de forma ínfima, el espectro de posibilidades de consideración conceptual al que nos proyecta el tema. La búsqueda nos ubica frente a la complejidad del universo de elaboraciones y la infinidad de formas desde las cuales se puede hablar de valores, de fundamentos éticos y de propuestas teóricas relativas al tema. De esta forma, decir valor, sin circunscribir en qué contexto referencial nos situamos, es decir muy poco, en la medida que si el tema no es situado corremos el riesgo de tomar la noción de valor como una noción vacía de contenido $y$, por ende, llenarla de un discurso fácilmente asimilable a la ideología, como un sistema de representaciones imaginarias con un fin poco explíci- 
to. En este sentido hablar de la responsabilidad, de la utilidad, de la perseverancia, etc., como valores, sin remitirlos a un sistema de conceptos que les den un sentido preciso, no pasa de ser una mera enunciación o un mero "palabreo". Por otra parte, la argumentación a la que hemos apelado pone en evidencia el esfuerzo de reflexión sobre problemas que gravitan en la esfera de lo humano, traducible a la consideración de los aspectos que fundamentan y tienen ingerencia en la vida de una sociedad determinada y que nos llenan de preguntas con respecto a las formas que adquieren determinados vínculos, a la forma cómo una historia con características específicas ha incidido en la manera en la que ciertos valores tienen más presencia que otros, a la vez que el inter-juego de lo que llamamos cultura se hace manifiesto en la presencia concreta de la relación entre iguales y diferentes en un contexto tan diverso como el de la sociedad ecuatoriana. Es así que la óptica desde la que indagamos, en la medida que se restringe a consideraciones de gran valor, en términos de definición y construcción de un sistema de conceptos que den cuenta de aspectos ético-axiológicos, requiere un esfuerzo de reflexión que los sitúe en un momento y en una realidad histórico-cultural concreta ${ }^{3}$. Siendo así que el perseverar puede ser un valor reconocido como importante en la educación, pero como tal, solamente, puede ser una forma de insistir en el error en un contexto político. La utilidad puede ser un valor que se considere necesario y relevante en el campo del uso racional de la tecnología, pero aparece reprochable si se constituye en un principio de las relaciones interpersonales, en la medida que no puedo utilizar a un otro como medio, sino como fin de mi actuar. Cuestión, la de la delimitación situacional a un contexto determinado y específico, que no aparece formulada de forma inmanente en las teorías a las que hemos apelado, por lo que se requiere, como problema, enunciar ciertas condiciones a partir de las cuales un planteo éticoaxiológico tenga vigencia y permita mirar una "realidad" determinada y delimitarla. De tal menera las ópticas que sitúen el desenvolvimiento histórico, cultural, político, social, psi-

3 En el sentido que Hegel le da a ese término en oposición a abstracto. En este sentido, concreto nos remite a un algo rico en determinaciones, correspondiendo a una consideración distinta de la que se hace en el lenguaje coloquial 
cológico y que devengan en un discurso ético-axiológico, permitirían la elaboración de esta temática de forma, como ya lo hemos enunciado, concreta.

El esquema referencial ideal que ubique los problemas relativos a una axiología no parece haber sido formulado, así como no contamos con desarrollos que den cuenta a cabalidad de los problemas que aparecen en el orden social, o en el orden psicológico.

\section{Aportes del psicoanálisis: construcción metapsicológica y valor}

En la perspectiva de este ensayo buscamos enriquecer, mediante el Psicoanálisis, el orden de problemas relativos al campo de los valores para poder mirar desde su óptica, la que incluye la puesta en crisis de la noción de conciencia y la dinámica del deseo, el lugar que desde lo psíquico tiene esta cuestión

El interés en el campo de los valores, desde la órbita psicoanalítica, puede ser situado en la perspectiva a la que apunta una consideración que busque circunscribir el problema de la organización subjetiva en función de un ordenamiento que de ser, en primer lugar, externo al sujeto, devenga en límite y organizador interno. Por lo que podemos referir que lo externo que se constituye en límite del sujeto pertenece al ámbito de lo que podemos delimitar como cultura. "...la cultura se edifica sobre la renuncia de lo pulsional, y cada individuo debe repetir en su persona, en el camino que va de la infancia a la madurez, ese desarrollo de la humanidad hacia una resignación razonable"4. Pero, ¿cómo se realiza esa renuncia? La fórmula freudiana es la de ubicar un paradigma de lo que se constituye como modelo de la prohibición: la posición del sujeto frente al complejo de Edipo. Tal cuestión pone freno a las pulsiones que buscan satisfacerse mediante la proscripción del incesto y el asesinato, a la vez que el sujeto busca, a través de la identificación, ser como el padre para poder tener a la madre. Pero ser como el padre es algo permitido, mas no tener a la madre. El freno a lo pulsional viene acompañado del asumir el modelo paterno, con sus características normativas, como el ideal con el 
que se compara y al que se busca parecer el sujeto. La relación amorodio en el vínculo con el padre al que el sujeto espera parecerse o ser como él, acompaña al odio que siente por ver frustrada su satisfacción pulsional y la rivalidad con el objeto parental que prohíbe, frustra o amenaza. El resultado de la represión pulsional hace que el Yo del sujeto se compare y se identifique con un ideal, al que le ligan afectos de orden positivo, mientras la frustración y el odio generan una instancia normativa interna que recibe el nombre de Súper Yo. Ambas instancias dentro del Yo, no están plenamente diferenciadas por Freud, no obstante, desde un aspecto dinámico-económico, generar procesos diferentes. El contenido valorativo se halla ligado a las representaciones que trasmite el modelo de identificación. Modelo a partir del cual se reproducen las formas en las que una cultura estatuye los referentes simbólicos que la caracterizan. Por otra parte el universo de representaciones al que apela el sujeto y que lo determinan, más allá de lo que la conciencia puede ubicar, vive una serie de procesos elaborativos en el acontecer psíquico que muestran su carácter y su fundamento en el conflicto por la renuncia y el dolor por la perdida o, si se puede hablar de esta manera, al dolor por la culpa ontológica (culpa por no ser todo).

El orden subjetivo es tal en función del límite, en un desenvolvimiento interno que no sólo pone freno al deseo, sino que lo trata de capturar en un movimiento incesante. El deseo se presentifica en lo psíquico a través de representaciones tanto ideativas como afectivas. Las primeras, son las únicas que pueden ser reprimidas con eficacia, mas no las afectivas que circulan libremente.

El problema del valor aparece ligado a un grupo de representaciones ideativas que enlazadas a lo normativo y al ideal, desempeñan un papel importante en la dinámica psíquica en especial superyóica. Pero al hablar de una normatividad que viene a ser asumida como propia mediante la identificación con modelos que aparecen en la experiencia de un sujeto determinado, en un momento temporal específico, en una familia o grupo primario de interrelación definido $y$, en general, en un ámbito que como exterioridad del sujeto posee ciertos códigos de organización, donde tales códigos no nos remiten a una legislación plasmada en un derecho positivo, sino a las reglas particulares de convivencia de una comunidad familiar, que aparece inscrita en un macro contexto social y cumple la función de transmisora 


\section{Alvaro Carrión}

de las pautas culturales que se constituyen en los referentes simbólicos de un determinado perímetro social, más la sui géneris elaboración que haga el sujeto, dependiendo del lugar, el momento y la situación de su propia prehistoria en la que como sujeto particular su existencia cobra presencia, nos vemos situados frente a tal cúmulo de mediaciones entre lo que se buscaría señalar como un valor y lo que finalmente y como producto un determinado sujeto reciba, que la transmisión, mediante la educación en valores como acción que ignore o descarte lo problemático de tal cuestión, queda absolutamente relativizado, a la vez que lo que llamamos valor y su contenido como representación debe tomar en cuenta el sinnúmero de mediaciones que condicionan su presencia concreta en un sujeto particular. Planteado lo anterior, volvemos a centrar la cuestión en la elaboración de la que podemos partir en la perspectiva de los desarrollos de Freud. Hay que tomar en cuenta, aunque esta recomendación pueda, a los entendidos, parecer de Perogrullo, que Freud no desarrolló un pensamiento o un interés por la axiología específicamente. Nuestros desarrollos parten de lo formulado por el psicoanalista austriaco en la segunda teoría del psiquismo.

El valor, decíamos, es una representación de la que se apropia el suje- to por vía identificatoria. Es desde esta perspectiva que el deseo y una estimación particular se juntan para dar a la "realidad" un estatuto, donde aquello considerado valioso cobra un especial brillo por vía identificatoria, en la medida que, en primer lugar, determinada representación es valorada explícita o implícitamente por el objeto con el que el Yo se identifica. En segundo lugar, una catexis o investidura específica liga al Yo con el objeto valorado, que es ya un segundo objeto, en el que se precipita la catexis o investidura como fruto de la cual surge el interés que representa para el sujeto el objeto apreciado. Esta dinámica nos proyecta no sólo a un campo axiológico donde una estimativa se produce y se plasma en objetos determinados, lo que reviste un interés general y no extraño a la estética por ejemplo, sino que adquiere una ubicuidad tal el eje ético-axiológico que deja sin efecto la aparente singularidad del campo estético y le da preferencia y primacía por sobre aquel, en un proceso que reviste una especial importancia en el concierto intra-psíquico, ya que esta última, la valoración, no aparece en lo psíquico como una simple estimativa, sino como lo que debe ser, lo que se debe elegir y lo que debe tener vigencia, como un imperativo que, a pesar de ser ajeno a la conciencia, se manifiesta como si fuera una elección 
propia del Yo-conciencia ${ }^{5}$. Esta forma de alienación, en la experiencia, prefigura y le da atributos a lo real, no reconociendo un algo de la construcción y el sentido que ese algo cobra, al mismo tiempo que el particular estatuto que se le da a "la realidad", fija y delimita el espacio que el Yo como sí mismo tiene frente al "mundo".

La vía de la identificación incluye otro camino, como movimiento inmanente y propio del mundo psíquico: el Yo se sitúa frente al Ello para posicionarse como objeto de este, suplantando al objeto que en primera instancia se ubica como el objeto de amor del Ello. Aquel objeto, decíamos, se trasforma de externo en interno, gracias al proceso de identificación, a la vez que resigna las metas sexuales, sublimándolas, al transformar, así, la libido de objeto en libido narcisista. Como resultado de este proceso, en clave estimativa, como ya lo referíamos, pasan a ser de externas, las representaciones, en cuanto a que pertenecen a un objeto con el que el Yo busca identificarse, a ser "la posición" que el Yo adopta frente a "la realidad", esto es internas al Yo.
La complexión de las identificaciones, en la medida que éstas no son depuradas en base a la racionalidad de un proceso secundario, son diversas y poco coherentes entre sí. Este carácter impide que aquellas sean análogas y afines con la unidad que busca el Yo, hecho por el cual podemos afirmar que éste es hijo del conflicto: una parte del Yo, que se escinde de él, el Super Yo, exige de éste ser acorde a un modelo y actuar en consonancia a pautas que le dicta una normativa que le rige desde lo interno. Al mismo tiempo que proscribe el deseo que parte del Ello y se ubica como instancia crítica del Yo si este cede a las demandas del Ello.

Otro proceso aparece en la explicación metapsicológica, que torna más complejo todavía el panorama. El Super Yo es el fruto de una escisión del Yo, como resultado de la dinámica de las identificaciones, en el que se ha plasmado una desexualización de la pulsión vía sublimación. Este proceso, en el que desempeña un papel protagónico el aspecto pulsional, pone sobre el tapete la dupla: pulsión de vida-pulsión de muerte.

5 Pensemos desde esta perspectiva el proceso repetitivo propio, en tanto repetición de lo igual, de la patología. A la vez que en la clausura narcisista, a partir de la cual el sujeto psíquico no puede ampliar el horizonte simbólico, hecho que le ata a una representación de si y del mundo que lo mantiene capturado. En este sentido, el eje narcisista ligado a la repetición del carácter ya enunciado, es una búsqueda incesante y desesperada de reafirmación del Ser, frente al peligro de la desorganización como ruptura de la unidad, a la vez que como repudio de la diferencia. 
El Super Yo recibe la energía pulsional del Ello, en una perspectiva en la que la desexualización torna fácil presa, a aquel, de la pulsión de muerte. Ésta, como sabemos, representa el aspecto más conservador de la pulsión, en la búsqueda de una satisfacción de carácter absoluto, por lo que una parte del psiquismo tiende a satisfacer una meta que le exige un gran esfuerzo y produce, a su vez, un gran conflicto. En un inicio el protosujeto, aquel que se halla en vías de constitución, busca satisfacer su deseo en forma absoluta. Pero en su calidad de sujeto finito no llega al absoluto de placer, por lo que rechaza al objeto de la "realidad", o, si se puede hablar en estos términos "odia" al objeto en el que no puede producir una descarga absoluta, ya que este no responde, en base a la identidad de percepción, al modelo de la primera experiencia de satisfacción, como paradigma de la satisfacción total. El sujeto en formación ama al objeto y lo odia, busca satisfacción y se muestra poco tolerante con la frustración de no poder producir una descarga total de libido. El objeto, que en un primer momento aparece como la "realidad", como el no Yo, en un segundo momento se lo delimita como la instancia que, como representante de la "realidad", en lo psíquico, media entre esta y las exigencias del Ello. Por ende dirige toda la fuerza de su agresividad al Yo, en la medida que éste representa la imposibilidad de lograr la satisfacción absoluta y le exige de forma severa que cumpla con lo que le exige la ley que norma y proscribe. Pero al mismo tiempo y mediante su exigencia busca anular al Yo y generar la satisfacción que espera. Fruto de esta dinámica encontramos al conflicto psíquico (como lucha entre instancias), al conflicto pulsional y al conflicto representacional. En este último caso, las normas que determinan conductas, conllevan valores, dictan pautas, están supeditadas a las vicisitudes de una subjetividad y a su fortaleza, donde la organización psíquica y el inter-juego tópico, dinámico y económico posibilitan o no la ínter subjetividad, en términos de una aceptación de la alteridad o, en su defecto, de un solipsismo que obtura la presencia del otro con mayúsculas o minúsculas y entorpece y subvierte los lazos sociales. De tal manera podemos proponer, desde un orden subjetivo, pensado desde el psicoanálisis, que para que se pueda pensar en la posibilidad de la presencia en los actos de valores que remitan a un nexo pregnado de eticidad, es condición necesaria la suerte que corra lo psíquico en su conformación. 
El sentido del valor o el valor en cuestión

\section{Bibliografía}

GARMENDIA DE CAMNUSSO,

Guillermina; FRONDIZI, Risieri

2004 La teoría del valor, en: Experiencia y filosofía: de la finitud a la eternidad, Buenos Aires, Ed. Colihue.

GOMÁ, Francisco

2003 Scheler y la ética de los valores, en: Historia de la ética, Barcelona, Ed. Crítica.

FREUD, Sigmund

1979 El yo y el ello, Buenos Aires, FREUD, Sigmund O.C., Amorrortu editores.

1979 Breve informe sobre el psicoanálisis, Buenos Aires, O.C., Amorrortu editores.
FRONDIZI, Risieri

1986 ¿Qué son los valores?, México, F.C.E.

FRONDIZI, Risieri

1977 Introducción a los problemas fundamentales del hombre, México, F.C.E.

LAING, R.D.

1976 Lo obvio, en: Hacia la locura, Madrid, Ed. Ayuso.

KANT, Emmanuel

1983 Fundamentación de la metafísica de las costumbres, Madrid, Ed. Espasa-Calpe.

SÁNCHEZ VÁSQUEZ, Adolfo

1984 Los valores, en: Ética, México, Ed. Grijalbo.

STERN, Alfred

1965 La filosofía de la historia y el problema de los valores, Buenos Aires, Ed. Eudeba. 